\title{
Body Composition Is an Independent Predictor of Outcome in Patients with Hepatocellular Carcinoma Treated with Sorafenib
}

\author{
Tim A. Labeur ${ }^{a, b}$ Jeroen L.A. van Vugt ${ }^{c}$ David W.G. Ten Cate ${ }^{c}$ \\ R. Bart Takkenberg ${ }^{d}$ Jan N.M. IJzermans ${ }^{c}$ Bas Groot Koerkamp ${ }^{c}$ \\ Robert A. de Man ${ }^{\text {e Otto M. van Delden }}{ }^{f}$ Ferry A.L.M. Eskens ${ }^{g}$ \\ Heinz-Josef Klümpen ${ }^{a, b}$

\begin{abstract}
${ }^{a}$ Cancer Center Amsterdam, Amsterdam, The Netherlands; ${ }^{b}$ Department of Medical Oncology, Amsterdam University Medical Centers, University of Amsterdam, Amsterdam, The Netherlands; ' ${ }^{\circ}$ Department of Surgery, Erasmus University Medical Center, Rotterdam, The Netherlands; ${ }^{d}$ Department of Gastroenterology and Hepatology, Amsterdam University Medical Centers, University of Amsterdam, Amsterdam, The Netherlands; ${ }^{\text {e Department }}$ of Gastroenterology and Hepatology, Erasmus University Medical Center, Rotterdam, The Netherlands; ${ }^{f}$ Department of Radiology, Amsterdam University Medical Centers, University of Amsterdam, Amsterdam, The Netherlands; 9 Department of Medical Oncology, Erasmus University Medical Center, Rotterdam, The Netherlands
\end{abstract}

\section{Keywords}

Hepatocellular carcinoma · Sorafenib · Body composition · Skeletal muscle mass · Total adipose tissue area $\cdot$ Prognosis

\begin{abstract}
Background: Previous studies have suggested body composition as a predictor of sorafenib toxicity and outcome in patients with advanced hepatocellular carcinoma (HCC). Large studies on the impact of body composition parameters in European HCC patients are lacking. Our aim was to validate the prognostic value of body composition parameters in Dutch patients with HCC treated with sorafenib. Patients and Methods: A retrospective analysis was performed in a cohort of HCC patients treated with sorafenib at two Dutch tertiary referral centers between 2007 and 2016. Body composition (adipose and skeletal muscle tissue) was measured at baseline by computed tomography (CT). Low skeletal muscle mass (SMM) and density were defined using published cut-offs. Body composition parameters were correlated with overall survival (OS), time to progression, response rate, and toxicity. Results: A total of 278 patients were included, mostly Child-Pugh class A (85\%) and Barcelona Clinic Liver Cancer (BCLC) stage $C(73 \%)$, with a median OS of 9.5 months ( $95 \% \mathrm{Cl} 8.1-11.0)$. Patients with combined low SMM and low total adipose tissue index (TATI) $(n=68,25 \%)$ had a poor median OS (5.8, 95\% Cl 4.8-6.8) compared with other patients (11.7, 95\% Cl 9.4-14.0). Combined low SMM
\end{abstract}


and low TATI remained an independent predictor of OS (HR 1.56, 95\% Cl 1.15-2.11, $p=0.004)$ after adjusting for known prognostic factors. There was no association between body composition and sorafenib toxicity. Conclusions: In Dutch HCC patients treated with sorafenib, the combined presence of low SMM and low TATI was associated with impaired survival, independent of known prognostic factors. CT assessment of body composition may provide additional prognostic information prior to sorafenib treatment.

(c) 2018 The Author(s)

Published by S. Karger AG, Basel

\section{Introduction}

For patients with advanced-stage hepatocellular carcinoma (HCC), the multi-kinase inhibitor sorafenib is the standard of care [1]. Sorafenib provides a median survival benefit of 3 months compared to placebo in patients with preserved liver function [2, 3]. Unfortunately, not all patients benefit from this treatment; in the landmark SHARP trial $27 \%$ of patients showed progressive disease at the first radiological evaluation [3]. Furthermore, potential survival benefit came at the cost of sorafenib-induced toxicity which resulted in dose reduction and interruption of treatment in 26 and $44 \%$ of patients, respectively. This indicates a large variability in sorafenib tolerability and survival outcomes. A recent post hoc analysis of 2 placebo-controlled studies showed greater survival benefit in patients with hepatitis C virus (HCV), liver-confined disease, or a low neutrophil-lymphocyte ratio (NLR) [4]. However, a precise prediction and personalized medicine is still far away from daily practice.

Host factors such as drug metabolism and distribution might affect sorafenib tolerability and efficacy. Sorafenib is a drug that is strongly lipophilic and has a large interpatient variation in bio-availability [5, 6], which may be affected by patients' body composition. Body composition, i.e., the amount and distribution of muscle and fat tissue, includes various parameters such as subcutaneous adipose tissue, visceral adipose tissue, and skeletal muscle tissue. Recently, altered body composition has been identified as a prognostic biomarker for treatment-related toxicity and poor survival in several malignancies [7-10]. Loss of skeletal muscle mass (SMM) is the most studied body composition parameter in cancer patients $[7,9$, 11 ] and was recently adopted as part of the cancer cachexia syndrome [8]. Combined loss of SMM and skeletal muscle function is defined as "sarcopenia" [12]. Loss of SMM is also a frequent complication of liver cirrhosis [13] and often represents an occult condition that can even be present in patients with normal or high body mass index (BMI) [8]. Computed tomography (CT) can easily and reliably quantify body composition parameters, including skeletal muscle and adipose tissue mass $[14,15]$, and is considered the gold standard for body composition measurements $[8,16]$. In HCC, prior studies identified CT-assessed low SMM, skeletal muscle density, and visceral adiposity as significant predictors of mortality in early-stage HCC patients $[11,17,18]$. An increase in the number of prognostic body composition components resulted in an increased mortality risk, suggesting a complementary effect of these parameters $[18,19]$. However, studies addressing the prognostic role of body composition in advanced-stage HCC have shown conflicting results [19-25]. These studies either had limited numbers of patients or were performed in Asian cohorts. A large-scale validation of the prognostic value of body composition parameters in a European cohort has not yet been performed and is warranted to translate these findings to this population.

Therefore, our primary aim was to validate whether CT-assessed body composition parameters are associated with survival in a Dutch cohort of patients with advanced HCC treated with sorafenib. Secondary aims were to assess the correlation of body composition with time to progression (TTP), response rate, and sorafenib toxicity. 


\section{Liver Cancer}

\begin{tabular}{l}
\hline Liver Cancer 2019;8:255-270 \\
\hline DOI: 10.1159/000493586
\end{tabular} \begin{tabular}{l}
$\begin{array}{l}\text { (c) 2018 The Author(s). Published by S. Karger AG, Basel } \\
\text { www.karger.com/lic }\end{array}$ \\
\hline
\end{tabular}

Labeur et al.: Body Composition Predicts Survival in Advanced HCC

\section{Methods}

\section{Study Population}

Consecutive patients with HCC, $\geq 18$ years old, who were treated with sorafenib from January 2007 to December 2016, were recruited to this retrospective study in two Dutch academic referral centers for HCC: Amsterdam University Medical Centers (Amsterdam UMC), location Academic Medical Center, Amsterdam, and Erasmus MC University Medical Center, Rotterdam. Patients were identified using pharmacy records, and keywords or diagnostic codes from the electronic patient registration systems. Included keywords were "hepatocellular carcinoma," "HCC," "malignancy liver," "liver neoplasm," and "liver malignant neoplasm." Patients receiving trial-based sorafenib were also included. Patients lacking assessable CT images or in whom body height was unknown were excluded. The study was performed in accordance with the Declaration of Helsinki and approved by the Institutional Review Board of the Amsterdam UMC which waived the need for informed consent (reference number W17_420\#17.488).

\section{Diagnostic Work-Up and Treatment Algorithm}

HCC diagnosis was established pathologically or radiologically by the European Association for the Study of the Liver imaging criteria [1]. Absence or presence of underlying cirrhosis was established using the criteria proposed by Mittal et al. [26]. All patients were staged by 4-phase CT or dynamic contrast-enhanced magnetic resonance imaging (MRI) and discussed at a multidisciplinary HCC tumor board. In accordance with the Barcelona Clinic Liver Cancer (BCLC) guidelines [1], patients with an Eastern Cooperative Oncology Group performance status (ECOG PS) 0-2 and BCLC stage C or BCLC stage B in whom transarterial chemoembolization (TACE) was not possible, were considered eligible for sorafenib treatment. Patients started with sorafenib at a dose of $200 \mathrm{mg}$ twice daily (b.i.d.) followed by toxicity-adjusted dosing up to the full dose (400 mg b.i.d.) in 1-2 weeks. Patients were allowed dose adjustments and treatment interruptions at the discretion of the medical oncologist to deal with sorafenib toxicity. Treatment response was assessed using CT or MRI with intervals of 2-3 months and evaluated by specialized abdominal radiologists using the Response Evaluation Criteria in Solid Tumors (RECIST) 1.1 criteria [27]. Sorafenib was continued until clinical or radiological disease progression, severe liver function deterioration (bilirubin $>51 \mu \mathrm{mol} / \mathrm{L}$ or Child-Pugh score >B8), or unacceptable toxicity as per institutional guidelines.

\section{Data Collection and Outcomes}

Medical records were reviewed and demographic, clinical, and imaging data were manually extracted. The primary outcome measure, overall survival (OS), was defined from the first dose of sorafenib to date of death or last follow-up. Survival status was assessed using the national civil registry on January 17, 2018. Patients alive at the last moment of follow-up were censored. TTP was defined as the time from start of sorafenib until clinical or radiological disease progression. Progression-free patients were censored at the time of the last radiological evaluation. Patients who died or were lost to follow-up before the first radiological evaluation were excluded from TTP analysis. In response evaluation, all patients who showed clinically progressive disease in the absence of radiological evaluation were considered to have progressive disease. All toxicities and treatment-emergent adverse events were classified according to the National Cancer Institute's Common Toxicity Criteria (NCI-CTC) v4.0 [28]. Liver dysfunction was defined as the occurrence or deterioration of hyperbilirubinemia (according to CTC $\mathrm{v} 4.0$ ), ascites, or encephalopathy.

\section{Body Composition Measurements}

Body weight $(\mathrm{kg})$ and height $(\mathrm{m})$ closest to treatment initiation were recorded from the medical charts, and body mass index (BMI, $\mathrm{kg} / \mathrm{m}^{2}$ ) was calculated. The population was divided into subgroups of patients with (BMI $\geq 25$ ) or without overweight (BMI $<25)$. Body composition measurements were conducted on CT images routinely performed for baseline tumor staging ( $\leq 4$ weeks prior to start). If unavailable (i.e., baseline MRI only), CT images $\leq 3$ months prior to start were used. The anonymized CT images were analyzed by one trained investigator (T.A.L.) using the FatSeg software package version 2.4 (Biomedical Imaging Group Rotterdam, Rotterdam, The Netherlands) as previously described [29]. In summary, skeletal muscle and adipose tissue compartments were manually outlined and measured using preset Hounsfield unit (HU) thresholds ( -30 to +150 and -190 to $-30 \mathrm{HU}$, respectively) at the level of the third lumbar vertebra (L3) where both transversal processes were visible (Fig. 1). Measurements at this anatomical landmark have been linearly related to whole-body measurements [14] and this method has a high inter- and intra-observer agreement [15]. Measured compartments were cross-sectional areas $\left(\mathrm{cm}^{2}\right)$ of skeletal muscle (SMA), subcu- 


\section{Liver Cancer}

\begin{tabular}{|c|c|}
\hline \multicolumn{2}{|l|}{ Liver Cancer 2019;8:255-270 } \\
\hline DOI: 10.1159/000493586 & $\begin{array}{l}\text { (c) } 2018 \text { The Author(s). Published by S. Karger AG, Basel } \\
\text { www.karger.com/lic }\end{array}$ \\
\hline
\end{tabular}

Labeur et al.: Body Composition Predicts Survival in Advanced HCC

Fig. 1. Cross-sectional CT image at the third lumbar vertebra used to quantify body composition variables. In this example, the skeletal muscle area (SMA) was manually outlined and highlighted in purple.

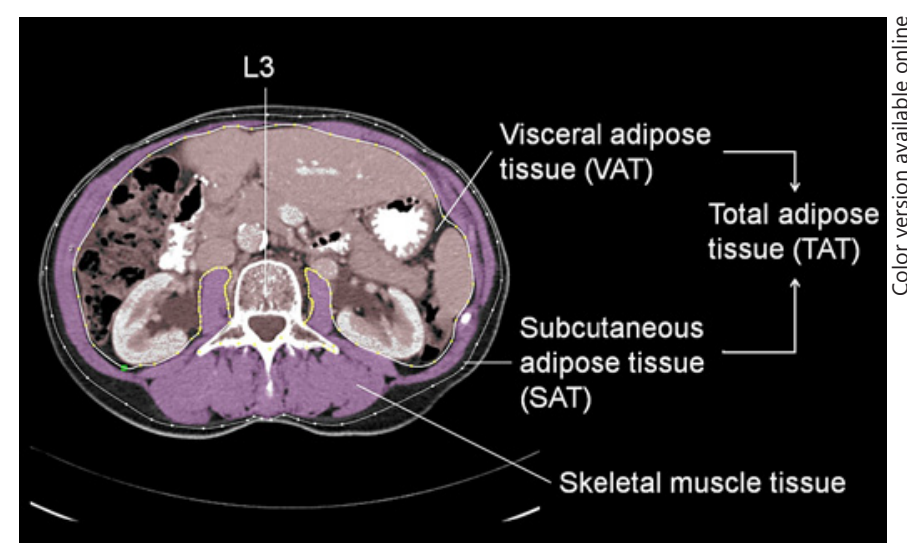

taneous adipose tissue (SATA), and visceral adipose tissue (VATA). Renal fat was included in the VATA, whereas intraluminal bowel contents with the same radiodensity as adipose tissue were manually erased. Total adipose tissue area $($ TATA $=$ SATA + VATA $)$ and visceral fat percentage $(($ VATA/TATA $) \times 100)$ were calculated. The mean skeletal muscle density, which is a measure of muscle density and skeletal muscle quality expressed in Hounsfield units (HU), was determined on all patients with contrast-enhanced CT images ( $n=267)$ as contrast enhancement influences tissue density [30].

All measured cross-sectional areas $\left(\mathrm{cm}^{2}\right)$ were normalized for patients' height squared, resulting in a skeletal muscle index (SMI; $\mathrm{cm}^{2} / \mathrm{m}^{2}$ ) and a total, visceral, and subcutaneous adipose tissue index (TATI, VATI, SATI; $\mathrm{cm}^{2} / \mathrm{m}$ ). Validated gender- and BMI-specific cut-off values, determined in a Western cohort of 1,473 patients with solid tumors, were used to define low SMM (low SMI) and low muscle density [9]. For total adipose tissue there are no internationally validated cut-offs. Therefore, the population was dichotomized into 2 groups: patients with high (above median) and low TATI (equal to or below median) subgroups. As fat distribution differs significantly according to gender, the population was divided into sex-specific high (above the sex-specific median) or low (equal to or below the sex-specific) VATI, SATI, and visceral fat percentage subgroups.

\section{Statistical Analysis}

Continuous variables were presented as medians with interquartile ranges (IQR), whereas categorical variables were expressed as counts and percentages. Categorical variables were compared with Fisher's exact or Pearson's $\chi^{2}$ test, whereas continuous variables were compared with the Student $t$ test or the MannWhitney U test. The correlation between BMI and other body composition parameters was expressed using Spearman's rank correlation coefficient ( $\rho$ ). Time to event data (OS, TTP) were estimated by the KaplanMeier method and compared using the log-rank test. The association between survival and body composition parameters was assessed in a multivariable Cox proportional hazards analysis, adjusting for known prognostic factors $[4,31]$ and additional factors that were associated with survival in univariable analysis $(p<$ 0.1). Hazard ratios (HR) with $95 \%$ confidence intervals (CI) were calculated. For all statistical tests described, a $p$ value of $<0.05$ was considered statistically significant. Statistical analyses were performed using IBM SPSS Statistics for Windows Version 23.0 (IBM Corp., Armonk, NY, USA).

\section{Results}

\section{Patient Characteristics}

Of the 323 consecutive patients who were treated with sorafenib between May 2007 and December 2016, we excluded 45 (14\%) patients because of missing body height or nonassessable CT images. Consequently, the study population consisted of 278 patients. Baseline characteristics and study outcomes (OS, TTP, toxicity) did not significantly differ between the included and excluded patients. 
Table 1. Baseline characteristics of the study cohort

\begin{tabular}{|c|c|}
\hline Characteristic & All patients $(n=278)$ \\
\hline \multicolumn{2}{|l|}{ Clinical parameters } \\
\hline Age, years & $64(57-70)$ \\
\hline \multirow{2}{*}{\multicolumn{2}{|c|}{ Etiology, $n(\%)$}} \\
\hline & \\
\hline Alcohol & $92(33)$ \\
\hline $\mathrm{HBV} / \mathrm{HCV}$ & $46 / 44(17 / 16)$ \\
\hline NAFLD-NASH & $19(7)$ \\
\hline Other/unknown & $17 / 71(6 / 26)$ \\
\hline Cirrhosis, $n(\%)$ & $213(77)$ \\
\hline \multicolumn{2}{|l|}{ Child-Pugh class ${ }^{\mathrm{a}}, n(\%)$} \\
\hline $\mathrm{A} / \mathrm{B}$ & $236 / 32(85 / 12)$ \\
\hline \multicolumn{2}{|l|}{ ECOG PS, $n(\%)$} \\
\hline $0 / 1 / 2$ & 98/158/22 (35/57/8) \\
\hline \multicolumn{2}{|l|}{ BCLC stage, $n(\%)$} \\
\hline Intermediate (B)/advanced (C) & $76 / 202(27 / 73)$ \\
\hline \multicolumn{2}{|l|}{ Number of nodes, $n(\%)$} \\
\hline $1 / 2-3 />3$ or diffuse infiltrating & $54 / 93 / 131(19 / 33 / 47)$ \\
\hline Size of largest node, $\mathrm{mm}$ & $70(40-110)$ \\
\hline \multirow{2}{*}{\multicolumn{2}{|c|}{ Extent of disease, $n(\%)$}} \\
\hline & \\
\hline Confined to liver/lymph nodes/other organ & $116 / 74 / 88(42 / 27 / 32)$ \\
\hline Received prior treatment for HCC, $n(\%)$ & $118(42)$ \\
\hline Liver transplantation/surgical resection & $5 / 41(2 / 15)$ \\
\hline RFA/TACE/SIRT & $42 / 58 / 19(15 / 21 / 7)$ \\
\hline Other systemic & $3(1)$ \\
\hline \multicolumn{2}{|l|}{ Laboratory analysis } \\
\hline AFP, ng/mL & $140(12-2794)$ \\
\hline $\mathrm{AFP} \geq 400 \mathrm{ng} / \mathrm{mL}, n(\%)$ & $109(39)$ \\
\hline Hemoglobin, $\mathrm{mmoL} / \mathrm{L}$ & $8.2(7.3-9.1)$ \\
\hline Thrombocytes, $\times 10^{9}$ & $184(124-272)$ \\
\hline Prothrombin time, s & $12.5(11.7-13.6)$ \\
\hline Albumin, g/dL & $40(36-43)$ \\
\hline Bilirubin, $\mu \mathrm{moL} / \mathrm{L}$ & $13(9-20)$ \\
\hline $\mathrm{NLR}^{\mathrm{b}}$ & $3.02(2.02-3.84)$ \\
\hline
\end{tabular}

The baseline characteristics of included patients are described in Table 1. The majority of patients were men (79\%), with a median age of 64 years (IQR 57-70). Alcohol was the most prevalent (33\%) underlying etiology, followed by chronic infection with hepatitis B virus (HBV; $17 \%$ ) or HCV (16\%). The majority of patients had cirrhosis (77\%), Child-Pugh class A liver function (85\%) and BCLC stage C HCC (73\%). The median largest tumor size was $70 \mathrm{~mm}$ (IQR $40-110 \mathrm{~mm}$ ), 41\% of patients had macrovascular invasion (MVI), and extrahepatic metastases were present in 59\%; $42 \%$ of patients had received prior treatment for HCC, mostly TACE (21\%).

\section{Body Composition Measurements}

The body composition features are summarized in Table 1. With the exception of BMI, muscle density, and TATI, all body composition parameters differed significantly between men and women. This reflects known gender differences such as higher SMM (median SMI 49.5 vs. $39.8, p<0.001$ ) and higher percentages of visceral fat in men (median 53 vs. $36 \%$, $p<0.001)$. Most patients (59\%) were considered overweight or obese (BMI $\geq 25.0)$. The BMI correlated strongly with adipose tissue indexes (TATI, VATI and SATI, $\rho=0.832,0.704$, and 
Labeur et al.: Body Composition Predicts Survival in Advanced HCC

Table 1 (continued)

\begin{tabular}{|c|c|c|c|}
\hline Body composition parameters & All patients & Male $(n=220)$ & Female $(n=58)$ \\
\hline BMI & $26(23-29)$ & $26(23-29)$ & $25(22-28)$ \\
\hline \multicolumn{4}{|l|}{ BMI category, $n(\%)$} \\
\hline Underweight $(<18.5)$ & $2(1)$ & $1(1)$ & $1(2)$ \\
\hline Normal (18.5-24.9) & $109(40)$ & $81(37)$ & $29(50)$ \\
\hline Overweight (25.0-29.9) & $113(41)$ & $97(44)$ & $19(33)$ \\
\hline Obese $(>30.0)$ & 49 (18) & 41 (19) & $9(16)$ \\
\hline \multicolumn{4}{|l|}{ Lumbar skeletal muscle tissue } \\
\hline SMI & $48.2(42.2-53.0)$ & $49.5(44.4-54.5)$ & $39.8(35.9-42.2)$ \\
\hline Low SMM, $n(\%)$ & $145(52)$ & $109(50)$ & $36(62)$ \\
\hline Muscle densityc, HU & $36(31-42)$ & $36(31-42)$ & $36(32-43)$ \\
\hline Low muscle density, $n(\%)$ & $114(41)$ & $88(40)$ & $26(45)$ \\
\hline \multicolumn{4}{|l|}{ Lumbar adipose tissue } \\
\hline Total fat ${ }^{\mathrm{d}}$ (TATI) & $109.9(75.1-155.5)$ & $117.4(77.4-156.4)$ & $96.9(66.9-149.8)$ \\
\hline Subcutaneous fat ${ }^{\mathrm{d}}$ (SATI) & $48.3(36.6-70.4)$ & $48.1(35.4-65.8)$ & $65.3(37.7-97.3)$ \\
\hline Visceral fat (VATI) & $56.1(29.3-85.5)$ & $63.0(38.5-92.0)$ & $29.6(20.6-55.4)$ \\
\hline Visceral fat percentage $\mathrm{e}^{\mathrm{d}}$ & $50(38-60)$ & $53(44-62)$ & $36(24-45)$ \\
\hline
\end{tabular}

Values in parentheses are IQR unless otherwise indicated. AFP, $\alpha$-fetoprotein; BCLC, Barcelona Clinic Liver Cancer classification; BMI, body mass index; ECOG PS, Eastern Cooperative Oncology Group performance status; HBV, hepatitis B virus; HCV, hepatitis C virus; IQR, interquartile range; NAFLD/NASH, nonalcoholic fatty liver disease/nonalcoholic steatohepatitis; RFA, radiofrequent ablation; SATI, subcutaneous adipose tissue index; SIRT, selective internal radiation therapy; SMI, skeletal muscle index; SMM, skeletal muscle mass; TACE, transcatheter arterial chemoembolization; TATI, total adipose tissue index; VATI, visceral adipose tissue index. ${ }^{\text {a }}$ Child-Pugh score was calculated in all patients (regardless of cirrhosis); data of 10 patients were missing. ${ }^{b}$ Data of 179 patients were missing. ${ }^{c}$ Data of 11 patients were excluded because of no contrast-enhancement. ${ }^{\mathrm{d}}$ Data of 34 patients were excluded because of incompletely displayed tissues.

0.723 , all $p<0.001)$, moderately with SMI $(\rho=0.500, p<0.001)$, and poorly with visceral fat percentage and muscle density ( $\rho=0.273$ and -0.343 , both $p<0.001)$.

A total of 145 (52\%) patients had low SMM, and 114 (41\%) had low skeletal muscle density. Patients with low SMM were older (median age 67 vs. 62 years, $p<0.001$ ), more often overweight or obese (66 vs. 53\%, $p=0.039$ ), had a lower muscle density (34 vs. $39 \mathrm{HU}, p<$ 0.001 ), and had a higher NLR (3.29 vs. $2.51, p=0.014$ ) than patients with high SMM. There were no significant differences in terms of Child-Pugh classification, disease extent, $\alpha$-fetoprotein (AFP) values, BCLC stage, and ECOG PS between these subgroups.

The median TATI, SATI, and VATI for all patients and stratified per sex are shown in Table 1. In 34 patients with severe overweight or obesity (median BMI 29.5), the L3 CT image did not entirely display the complete subcutaneous fat area, prohibiting complete measurement of this body composition compartment. To avoid exclusion bias, median SATI and TATI values were determined in adequately measured patients $(n=244)$, and the 34 patients were categorized based on their measured, albeit underestimated, SATI and TATI.

\section{Association of Body Composition Parameters with OS}

After a median follow-up of 54.9 months (IQR 39.0-63.2), 255 (92\%) patients had died. The median OS was 9.5 months (95\% CI 8.0-11.0). Patients with a low TATI had a significantly poorer survival than patients with a high TATI (7.3 vs. 11.9 months, log-rank $p=0.006$ ) (Fig. 2c). Low SMM (Fig. 2a), low muscle density, low VATI, low SATI, low visceral fat percentage, or BMI $\geq 25$ were not significantly associated with OS (Table 2). Besides low TATI (HR 1.42, 95\% CI 1.11-1.82, $p=0.006$ ), other baseline factors that were significantly associated with decreased OS in univariable analysis included Child-Pugh class B, ECOG PS 2, size 


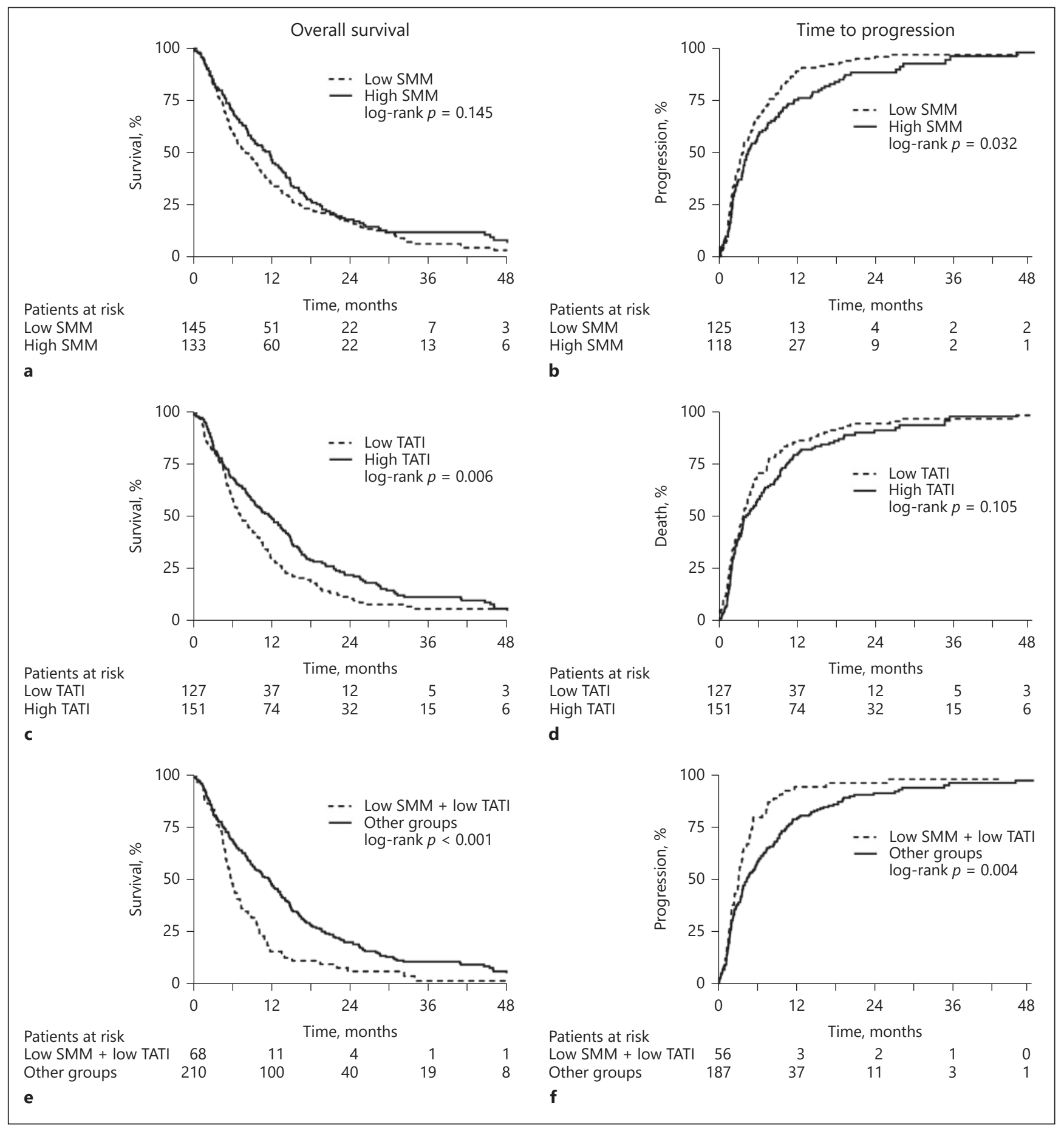

Fig. 2. Overall survival and time to progression (TTP) curves according to body composition parameters. a, b Patients with low and high skeletal muscle mass (SMM). c, d Patients with high and low total adipose tissue index (TATI). e, f Patients with and without combined low SMM and low TATI. Unavailable for TTP analysis, $n=35$. 
Labeur et al.: Body Composition Predicts Survival in Advanced HCC

Table 2. Univariable and multivariable Cox regression analyses for overall survival

\begin{tabular}{|c|c|c|c|c|c|c|}
\hline & \multicolumn{3}{|c|}{ Univariable analysis } & \multicolumn{3}{|c|}{ Multivariable analysis } \\
\hline & HR & $95 \%$ CI & $p$ value & HR & $95 \%$ CI & $p$ value \\
\hline \multicolumn{7}{|l|}{ Body composition variables } \\
\hline Low SMM & 1.20 & $0.94-1.54$ & 0.417 & & & \\
\hline Low muscle density & 0.97 & $0.75-1.24$ & 0.782 & & & \\
\hline Low TATI ${ }^{\mathrm{a}}$ & 1.42 & $1.11-1.82$ & 0.006 & & & \\
\hline Low SATI & 1.20 & $0.94-1.53$ & 0.154 & & & \\
\hline Low VATI & 1.19 & $0.93-1.52$ & 0.172 & & & \\
\hline Low visceral fat percentage & 0.97 & $0.76-1.24$ & 0.808 & & & \\
\hline BMI $\geq 25$ (ref: $<25$ ) & 0.82 & $0.64-1.05$ & 0.118 & & & \\
\hline Low SMM + low TATI & 1.77 & $1.33-2.35$ & $<0.001$ & 1.56 & $1.15-2.11$ & 0.004 \\
\hline \multicolumn{7}{|l|}{ Other baseline variables } \\
\hline Female sex & 1.26 & $0.93-1.71$ & 0.131 & & & \\
\hline Age $>65$ years & 0.87 & $0.68-1.12$ & 0.277 & & & \\
\hline HBV & 1.20 & $0.86-1.68$ & 0.294 & & & \\
\hline $\mathrm{HCV}$ & 0.97 & $0.68-1.37$ & 0.844 & & & \\
\hline Alcohol & 1.00 & $0.77-1.29$ & 0.967 & & & \\
\hline Child-Pugh B (ref: Child-Pugh A) & 2.38 & $1.62-3.49$ & $<0.001$ & 2.30 & $1.56-3.41$ & $<0.001$ \\
\hline ECOG PS (ref: ECOG PS 0) & & & 0.002 & & & 0.030 \\
\hline ECOG PS 1 & 1.22 & $0.93-1.59$ & & 1.10 & $0.83-1.45$ & \\
\hline ECOG PS 2 & 2.40 & $1.48-3.89$ & & 1.99 & $1.19-3.33$ & \\
\hline BCLC stage C (ref: B) & 1.21 & $0.91-1.59$ & 0.187 & & & \\
\hline Number of nodes (ref: 1 node) & & & 0.152 & & & \\
\hline $2-3$ nodes & 0.87 & $0.61-1.24$ & & & & \\
\hline >3 nodes/diffuse infiltrating & 1.15 & $0.83-1.60$ & & & & \\
\hline Tumor size $>70 \mathrm{~mm}$ & 1.54 & $1.20-2.00$ & 0.001 & 1.27 & $0.96-1.67$ & 0.090 \\
\hline Macroscopic vascular invasion & 1.44 & $1.12-1.85$ & 0.005 & 1.25 & $0.96-1.64$ & 0.095 \\
\hline Presence of extrahepatic metastases (ref: none) & & & 0.792 & & & \\
\hline Lymph nodes & 1.13 & $0.83-1.54$ & & & & \\
\hline Other organ & 1.08 & $0.81-1.45$ & & & & \\
\hline High NLR ${ }^{\mathrm{b}}$ & 1.70 & $1.12-2.58$ & 0.012 & & & \\
\hline $\mathrm{AFP} \geq 400 \mathrm{ng} / \mathrm{mL}$ & 1.93 & $1.49-2.51$ & $<0.001$ & 1.81 & $1.38-2.37$ & $<0.001$ \\
\hline Received previous treatments & 0.66 & $0.51-0.85$ & 0.001 & 0.83 & $0.63-1.10$ & 0.188 \\
\hline
\end{tabular}

of largest tumor $>70 \mathrm{~mm}$ (above median), MVI, high NLR (above median), and AFP $\geq 400 \mathrm{ng}$ / $\mathrm{mL}$ (Table 2). Patients who received prior HCC treatment had a better OS. NLR was not included in the multivariable analysis due to large numbers of missing values ( $n=179,65 \%)$. In multivariable analysis, low TATI was no longer significantly associated with OS after correction for other predictors of mortality (HR 1.28, 95\% CI 0.98-1.66, $p=0.072$ ) (online suppl. Table 1; for all online suppl. material, see www.karger.com/doi/10.1159/000493586).

\section{Association of Body Composition Parameters with TTP and Response Rate}

A total of 243 patients were available for TTP analysis; 35 patients (13\%) could not be evaluated because they died or were lost to follow-up before clinical or radiological disease progression. The median TTP was 3.9 months (95\% CI 3.2-4.5). Patients with low SMM showed 
Labeur et al.: Body Composition Predicts Survival in Advanced HCC

Table 3. Univariable and multivariable Cox regression analyses for time to progression

\begin{tabular}{|c|c|c|c|c|c|c|}
\hline & \multicolumn{3}{|c|}{ Univariable analysis } & \multicolumn{3}{|c|}{ Multivariable analysis } \\
\hline & HR & $95 \% \mathrm{CI}$ & $p$ value & HR & $95 \% \mathrm{CI}$ & $p$ value \\
\hline \multicolumn{7}{|l|}{ Body composition variables } \\
\hline Low SMM & 1.33 & $1.02-1.74$ & 0.033 & 1.35 & $1.01-1.81$ & 0.042 \\
\hline Low muscle density & 1.01 & $0.77-1.32$ & 0.970 & & & \\
\hline Low TATI & 1.24 & $0.95-1.62$ & 0.107 & & & \\
\hline Low SATI & 1.07 & $0.82-1.39$ & 0.608 & & & \\
\hline Low VATI & 1.21 & $0.93-1.58$ & 0.149 & & & \\
\hline Low visceral fat percentage & 1.14 & $0.87-1.48$ & 0.325 & & & \\
\hline BMI $\geq 25$ (ref: $<25$ ) & 0.92 & $0.70-1.20$ & 0.543 & & & \\
\hline Low SMM and low TATI ${ }^{\mathrm{a}}$ & 1.57 & $1.15-2.14$ & 0.005 & & & \\
\hline \multicolumn{7}{|l|}{ Other baseline variables } \\
\hline Female sex & 1.46 & $1.05-2.03$ & 0.025 & 1.44 & $1.01-2.06$ & 0.043 \\
\hline Age $>65$ years & 0.82 & $0.63-1.07$ & 0.146 & & & \\
\hline HBV & 1.45 & $1.02-2.05$ & 0.037 & 1.36 & $0.94-1.96$ & 0.103 \\
\hline $\mathrm{HCV}$ & 0.91 & $0.63-1.32$ & 0.621 & & & \\
\hline Alcohol & 0.84 & $0.64-1.11$ & 0.224 & & & \\
\hline Child-Pugh B (ref: Child-Pugh A) & 1.59 & $1.04-2.43$ & 0.031 & 1.50 & $0.97-2.31$ & 0.070 \\
\hline ECOG PS (ref: ECOG PS 0) & & & 0.027 & & & \\
\hline ECOG PS 1 & 1.07 & $0.80-1.42$ & & 0.97 & $0.72-1.30$ & \\
\hline ECOG PS 2 & 1.96 & $1.19-3.22$ & & 1.63 & $0.96-2.78$ & \\
\hline BCLC stage $C^{b}$ (ref: $\left.B\right)$ & 1.50 & $1.10-2.06$ & 0.012 & & & \\
\hline Number of nodes (ref: 1 node) & & & 0.408 & & & \\
\hline 2-3 nodes & 1.13 & $0.77-1.66$ & & & & \\
\hline >3 nodes/diffuse infiltrating & 1.27 & $0.88-1.83$ & & & & \\
\hline Tumor size $>70 \mathrm{~mm}$ & 1.35 & $1.04-1.76$ & 0.025 & 1.10 & $0.82-1.48$ & 0.524 \\
\hline Macroscopic vascular invasion & 1.46 & $1.12-1.91$ & 0.005 & 1.37 & $1.03-1.81$ & \\
\hline Presence of extrahepatic metastases (ref: none) & & & 0.208 & & & \\
\hline Lymph nodes & 1.28 & $0.93-1.78$ & & & & \\
\hline Other organ & 1.27 & $0.93-1.74$ & & & & \\
\hline Received previous treatments & 0.81 & $0.62-1.05$ & 0.114 & & & \\
\hline High NLR $^{\mathrm{c}}$ & 1.81 & $1.16-2.83$ & & & & \\
\hline $\mathrm{AFP} \geq 400 \mathrm{ng} / \mathrm{mL}$ & 1.74 & $1.32-2.28$ & $<0.001$ & 1.84 & $1.37-2.46$ & $<0.001$ \\
\hline
\end{tabular}

AFP, $\alpha$-fetoprotein; BCLC, Barcelona Clinic Liver Cancer classification; BMI, body mass index; ECOG PS, Eastern Cooperative Oncology Group performance status; HBV, hepatitis B virus; HCV, hepatitis C virus; SATI, subcutaneous adipose tissue index; SMM, skeletal muscle mass; TATI, total adipose tissue index; VATI, visceral adipose tissue index. ${ }^{\text {a }}$ Not included in multivariable analysis due to collinearity with low SMM (model shown in online suppl. Table 2). ${ }^{b}$ Not included in multivariable analysis to reduce overlapping variance (multicollinearity). ${ }^{\mathrm{c}}$ Not included in multivariable analysis due to large numbers of missing values $(n=179)$.

significantly shorter TTP compared with patients with high SMM (3.5 vs. 4.4 months, $p=0.032$ ) (Fig. 2b). Other body composition parameters showed no statistically significant association with TTP (Table 3). Additional univariable predictors of TTP were female sex, presence of HBV, Child-Pugh class B, ECOG PS, BCLC stage, MVI, high NLR, and AFP $\geq 400 \mathrm{ng} / \mathrm{mL}$ (Table 3). NLR was not included in the multivariable analysis due to large numbers of missing values $(n$ $=179,65 \%)$. Low SMM remained significantly associated with reduced TTP (HR 1.35, 95\% CI 1.01-1.81, $p=0.042$ ) after correction for known predictors in multivariable analysis.

According to the RECIST criteria, $10 \%$ of the patients had a partial response, $37 \%$ stable disease, and $41 \%$ progressive disease (online suppl. Table 3). There were no statistically significant associations between response rates and BMI, SMM, muscle density, TATI, VATI, SATI, or visceral fat percentage. 
Fig. 3. Overall survival (a) and time to progression (TTP) (b) curves in patients according to the combination of low or high SMM and TATI. Unavailable for TTP analysis, $n=35$.

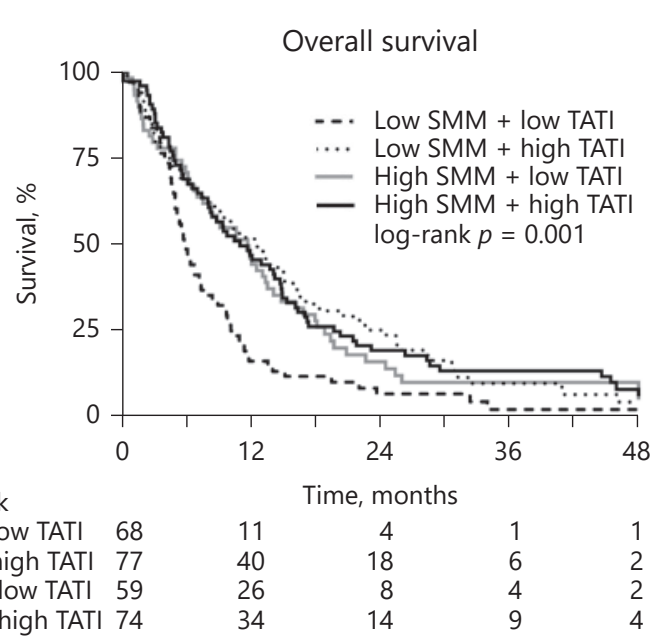

Patients at risk Low SMM + low TATI 68 Low SMM + high TATI 77 High SMM + low TATI 59 High SMM + high TATI 74

a

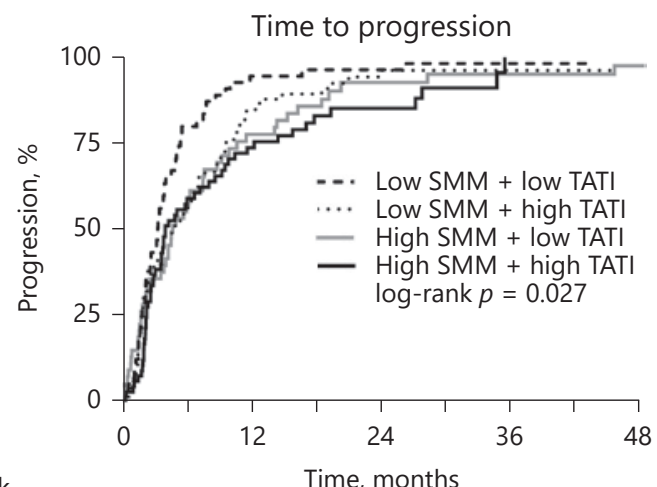

Patients at risk Low SMM + low TATI 56 Low SMM + high TATI 69 High SMM + low TATI 53 High SMM + high TATI 65 b 
Combined low SMM and low TATI was present in 68 patients (25\%) and relatively more common in women than men ( $45 \mathrm{vs.} 19 \%, p<0.001$ ). These patients had a significantly lower BMI (24 vs. 27, $p<0.001$ ) than other patients. Moreover, these patients had lower hemoglobin ( 7.4 vs. $8.5 \mathrm{mmol} / \mathrm{L}, p<0.001$ ) and albumin ( $38 \mathrm{vs.} 40 \mathrm{~g} / \mathrm{dL}, p=0.026$ ) levels. There were no significant differences in age, disease etiology, Child-Pugh status, ECOG PS, BCLC stage, tumor number, or tumor extent compared with other patients.

Patients who had low SMM and a low TATI showed a significantly poorer survival (5.8 months, 95\% CI 9.4-14.0) than patients with only one or no altered body composition parameter (11.7 months, 95\% CI 4.8-6.8, $p<0.001$ ) (Fig. 2e, 3a). In a multivariable model corrected for Child-Pugh status, ECOG PS, MVI, tumor size, AFP levels, and prior HCC treatments, combined low SMM and low TATI remained significantly associated with poor survival (HR 1.56, 95\% CI 1.15-2.11, $p=0.004$ ) (Table 2). Other predictors of mortality included Child-Pugh class B (HR 2.30, 95\% CI 1.56-3.41), ECOG PS 2 (HR 1.99, 95\% CI 1.19-3.33), and $\mathrm{AFP} \geq 400 \mathrm{ng} / \mathrm{mL}$ (HR 1.81, 95\% 1.38-2.37). In both subgroups of patients with ECOG PS 0-1 and ECOG PS 2, there was a clear stratification in patients with and without combined low SMM and low TATI (data not shown).

Combined low SMM and low TATI was associated with reduced TTP (3.2 months, 95\% CI 2.4-4.0) compared with other subgroups (4.4 months, 95\% CI 3.2-5.7, log-rank $p=0.004$ ) (Fig. 2f, 3b). Although this was a predictor for TTP in univariable analysis (HR 1.57, 95\% CI $1.15-2.14, p=0.005$ ), it was no longer significant (HR 1.36, 95\% CI 0.95-1.93, $p=0.091$ ) after correction for known predictors (online suppl. Table 2). Patients with low SMM and low TATI had significantly shorter treatment duration (11 vs. 16 weeks, $p=0.028)$ and more hematological toxicity (18 vs. $6 \%, p=0.004$ ) than other patients. There were no significant differences in response rate or treatment-emergent adverse events.

\section{Discussion}

This is the largest multicenter study in a European country to analyze the prognostic impact of CT-assessed body composition parameters in HCC patients treated with sorafenib. We found that low SMM alone was associated with shorter TTP, but not with OS. Presence of combined low SMM and low TATI was associated with poor OS, also after correcting for known prognostic factors. Therefore, body composition should be considered as a new prognostic factor in advanced HCC.

Body composition parameters, especially low SMM, are associated with OS and treatment toxicity in early-stage HCC [18, 32-34]. In our study, low SMM was not significantly associated with OS. These differences may reflect that low SMM has a bigger impact on patients treated with surgical resection, mainly due to increased surgery-related morbidity and mortality [33, 34]. Studies on the impact of body composition parameters in patients treated with sorafenib are scarce and outcomes conflicting (Table 4). Our data are in concordance with 2 other studies in European cohorts [22, 23], but not in concordance with 4 studies in Japanese patients which reported a significant impact of low SMM on OS [20,21,24,25]. The difference between European and Japanese studies might be explained by different cut-offs for low SMM used in European and Japanese studies. Data on the clinical relevance of ethnical differences in body composition on sorafenib outcome and international consensus on cut-off values for CT-based low SMM is lacking. Moreover, comparison of Asian and European cohorts is difficult due to known differences in baseline characteristics (i.e., HCC etiology) and sorafenib outcomes [2,3]. Future international studies are needed to refine the currently used cut-off values for body composition parameters in patients with chronic liver disease. 
Table 4. Studies on the impact of body composition on sorafenib outcomes

\begin{tabular}{|c|c|c|c|}
\hline $\begin{array}{l}\text { Outcome/ } \\
\text { body composition parameter }\end{array}$ & Correlation & $\begin{array}{l}\text { Diagnosis } \\
\text { (patients, } n \text { ) }\end{array}$ & Reference \\
\hline \multicolumn{4}{|l|}{ Overall survival } \\
\hline \multirow{7}{*}{ Skeletal muscle index } & Yes & HCC (232) & Nishikawa et al. [24] \\
\hline & Yes & $\operatorname{HCC}(40)$ & Imai et al. [21] \\
\hline & Yes & HCC (214) & Takada et al. [25] \\
\hline & Yes & HCC (100) & Saeki et al. [19] \\
\hline & No & HCC (52) & Nault et al. [23] \\
\hline & No & HCC (40) & Mir et al. [22] \\
\hline & No & HCC (278) & Labeur et al. \\
\hline \multirow[t]{2}{*}{ Psoas muscle index } & Yes & HCC (93) & Hiraoka et al. [20] \\
\hline & No & HCC (40) & Yamashima et al. [19] \\
\hline Muscle density & No & HCC (278) & Labeur et al. \\
\hline \multirow[t]{2}{*}{ SATI } & No & HCC (52) & Nault et al. [23] \\
\hline & No & HCC (278) & Labeur et al. \\
\hline \multirow[t]{3}{*}{ VATI } & Yes & HCC (52) & Nault et al. [23] \\
\hline & Yes & HCC (100) & Saeki et al. [19] \\
\hline & No & HCC (278) & Labeur et al. \\
\hline TATI & No & HCC (278) & Labeur et al. \\
\hline Visceral fat percentage & No & HCC (278) & Labeur et al. \\
\hline \multirow[t]{3}{*}{ BMI } & No & HCC (40) & Imai et al. [21] \\
\hline & No & HCC (52) & Nault et al. [23] \\
\hline & No & HCC (278) & Labeur et al. \\
\hline \multirow[t]{2}{*}{ Muscle + fat (complementary) } & Yes & HCC (100) & Saeki et al. [19] \\
\hline & Yes & HCC (278) & Labeur et al. \\
\hline \multicolumn{4}{|l|}{ Toxicity } \\
\hline \multirow[t]{5}{*}{ Skeletal muscle index } & Yes & RCC (55) & Antoun et al. [35] \\
\hline & Yes & HCC (40) & Mir et al. [22] \\
\hline & Yes & HCC (52) & Nault et al. [23] \\
\hline & No & HCC (214) & Takeda et al. [25] \\
\hline & No & HCC (278) & Labeur et al. \\
\hline Lean body mass & No & HCC (52) & Nault et al. [23] \\
\hline Muscle density & No & HCC (278) & Labeur et al. \\
\hline \multirow[t]{3}{*}{ SATI } & No & $\operatorname{HCC}(40)$ & Mir et al. [22] \\
\hline & No & HCC (52) & Nault et al. [23] \\
\hline & No & HCC (278) & Labeur et al. \\
\hline \multirow[t]{3}{*}{ VATI } & No & HCC (40) & Mir et al. [22] \\
\hline & No & HCC (52) & Nault et al. [23] \\
\hline & No & HCC (278) & Labeur et al. \\
\hline \multirow[t]{3}{*}{ TATI } & No & RCC (55) & Antoun et al. [35] \\
\hline & No & HCC (40) & Mir et al. [22] \\
\hline & No & HCC (278) & Labeur et al. \\
\hline Visceral fat percentage & No & HCC (278) & Labeur et al. \\
\hline
\end{tabular}


Labeur et al.: Body Composition Predicts Survival in Advanced HCC

Table 4 (continued)

\begin{tabular}{|c|c|c|c|}
\hline $\begin{array}{l}\text { Outcome/ } \\
\text { body composition parameter }\end{array}$ & Correlation & $\begin{array}{l}\text { Diagnosis } \\
\text { (patients, } n \text { ) }\end{array}$ & Reference \\
\hline BMI & $\begin{array}{l}\text { Yes } \\
\text { No } \\
\text { No }\end{array}$ & $\begin{array}{l}\text { RCC (55) } \\
\text { HCC (40) } \\
\text { HCC (278) }\end{array}$ & $\begin{array}{l}\text { Antoun et al. [35] } \\
\text { Mir et al. [22] } \\
\text { Labeur et al. }\end{array}$ \\
\hline $\mathrm{BSA}$ & No & HCC (40) & Mir et al. [22] \\
\hline Muscle + fat (complementary) & No & HCC (278) & Labeur et al. \\
\hline
\end{tabular}

Reference Labeur et al. refers to the present study. BMI, body mass index; BSA, body surface area; HCC, hepatocellular carcinoma; RCC, renal cell carcinoma; SATI, subcutaneous adipose tissue index; SMI, skeletal muscle index; TATI, total adipose tissue index; VATI, visceral adipose tissue index.

With regards to toxicity, low SMM has been associated with increased sorafenib exposure and dose-limiting toxicity in both advanced-stage HCC and renal cell carcinoma [22, 23, 35]. Nevertheless, in our study none of the body composition parameters was significantly associated with increased sorafenib toxicity or reduced maximum tolerated dose. Our findings are in concordance with Takada et al. [25], who also reported applying dose reductions in patients at high age or in those experiencing adverse events. These discrepancies may be explained by variations in clinical practice. In our practice, patients started half dose (200 mg b.i.d.) with toxicity-adjusted dosing to full dose (400 mg b.i.d.), as opposed to starting full-dose sorafenib in prior studies. Lower starting doses with tolerability-based dose escalation have been shown to decrease the rates of sorafenib discontinuation due to adverse events [36].

Combined low SMM and low TATI was associated with the poorest survival in this study. Clinical features of this subgroup (lower muscle and fat index, lower hemoglobin, lower albumin) reflect a poor nutritional state that meets the criteria of cancer cachexia [8]. These results are in concordance with 2 prior studies showing a complementary effect of body composition components on HCC outcomes $[18,19]$. This is also in concordance with the current consensus that cachexia severity is a continuum with various stages of severity [8]. Currently used prognostic scores for assessing clinical performance and severity of disease (i.e. ECOG PS, BCLC stage, Child-Pugh) were not significantly different to other patients and thus are not suitable to detect these patients. These scoring systems also have significantly inter-observer variability. BMI only correlated strongly with fat indexes (TATI, SATI and VATI), but poorly with muscle index. Presence of ascites might also cause an overestimation of BMI. Considering the limitations of current prognostic clinical scores and BMI, body composition assessment on baseline CT images can be a useful noninvasive clinical tool that is technically easy to implement. Moreover, body composition may be used to stratify patients in randomized clinical trials comparing new agents with sorafenib.

Whether and how the outcomes of patient with unfavorable body composition can be improved remains debatable. First, a better understanding of the complex hormonal, inflammatory, and metabolic alterations in liver cirrhosis and HCC is needed [13, 37]. Sorafenib undergoes extensive biotransformation to several active metabolites [38], but the role of altered host metabolism is poorly understood. Based on the current evidence, improving outcomes in patients with cachexia may be possible with a multimodal approach (nutritional support, exercise, pharmacological agents) $[8,39]$. However, this might not be superior to symptom palliation in case of severe cachexia. Therefore, future prospective trials aiming to 
counteract cachexia and subsequently improve outcomes of these patients should compare a multimodal intervention with symptom palliation only [7].

The main limitation of our study is the retrospective design and its inherent limitations. Firstly, the exclusion of patients because of non-availability of CT images or documented body height might have caused selection bias. Furthermore, retrospective assessment of sorafenib outcomes is prone to reporting bias. Nevertheless, there were no differences in baseline characteristics between the included and excluded patients, and primary (OS) and secondary outcomes (TTP, response rate, toxicity) were comparable with previous large series [31, 40]. The risk of selection bias was reduced by including patients with CT images 1-3 months prior to sorafenib initiation, who did not have statistically significant differences in body composition compared with patients who had CT imaging $\leq 4$ weeks prior to start. Despite these limitations, our study is the largest validation of the prognostic value of body composition parameters in HCC patients treated with sorafenib in a European country. The standardized assessment of all patients in a multidisciplinary team meeting and prospective response evaluation allowed for the assembly of a robust dataset. Therefore, our study may be considered representative for the daily clinical practice of a European tertiary referral center for HCC.

In conclusion, in Dutch HCC patients treated with sorafenib, combined low SMM and low TATI was associated with impaired survival, independent of known predictors. CT assessment of body composition is a valid method providing additional prognostic information prior to sorafenib treatment. Future prospective trials should investigate the pathophysiology of altered body composition and determine whether an intervention can reverse this nutritional status and improve outcomes.

\section{Statement of Ethics}

The study was performed in accordance with the Declaration of Helsinki and approved by the Institutional Review Board of the Amsterdam University Medical Centers which waived the need for informed consent (Ref. No. W17_420\#17.488).

\section{Disclosure Statement}

Heinz-Josef Klümpen is member of the advisory board for Ipsen and Sirtex, and received an unrestricted research grant from Bayer (no grant numbers apply). R. Bart Takkenberg served as a speaker for Gore WL, Bayer, and Norgine, and is a member of the advisory board for Gilead. Robert A. de Man served as a speaker for Norgine and as a consultant for Cook Medical. Otto M. van Delden served as consultant for Cook Medical. All other authors have declared no conflicts of interest.

\section{Funding Sources}

This research received no specific grant from any funding agency in the public, commercial, or not-forprofit sectors.

\section{Author Contributions}

Dr. H.-J. Klümpen acted as guarantor of the article. T.A.L. led the study, performed data acquisition and analysis, and wrote the manuscript. J.L.A.V. and D.W.G.C. performed data acquisition. J.L.A.V., R.B.T., J.N.M.I., B.G.K., R.A.M., O.M.D., F.A.L.M.E., and H.-J.K. conceived the study design, supervised the study, provided data and clinical input, and provided mentorship for the study. All authors reviewed and approved the final version of the manuscript. This study was endorsed by the Dutch Hepato \& Cholangio Carcinoma Group (DHCG). 
Labeur et al.: Body Composition Predicts Survival in Advanced HCC

\section{References}

1 European Association for the Study of the Liver European Organisation for Research and Treatment of Cancer. EASL-EORTC clinical practice guidelines: management of hepatocellular carcinoma. J Hepatol. 2012 Apr; 56(4):908-43.

2 Cheng AL, Kang YK, Chen Z, Tsao CJ, Qin S, Kim JS, et al. Efficacy and safety of sorafenib in patients in the AsiaPacific region with advanced hepatocellular carcinoma: a phase III randomised, double-blind, placebocontrolled trial. Lancet Oncol. 2009 Jan;10(1):25-34.

3 Llovet JM, Ricci S, Mazzaferro V, Hilgard P, Gane E, Blanc JF, et al.; SHARP Investigators Study Group. Sorafenib in advanced hepatocellular carcinoma. N Engl J Med. 2008 Jul;359(4):378-90.

4 Bruix J, Cheng AL, Meinhardt G, Nakajima K, De Sanctis Y, Llovet J. Prognostic factors and predictors of sorafenib benefit in patients with hepatocellular carcinoma: analysis of two phase III studies. J Hepatol. 2017 Nov;67(5):999-1008.

5 EU Summary of Product Characteristics for Nexavar. Berlin, Bayer Schering Pharma AG, 2011.

6 Hornecker M, Blanchet B, Billemont B, Sassi H, Ropert S, Taieb F, et al. Saturable absorption of sorafenib in patients with solid tumors: a population model. Invest New Drugs. 2012 Oct;30(5):1991-2000.

7 Bozzetti F. Forcing the vicious circle: sarcopenia increases toxicity, decreases response to chemotherapy and worsens with chemotherapy. Ann Oncol. 2017 Sep;28(9):2107-18.

8 Fearon K, Strasser F, Anker SD, Bosaeus I, Bruera E, Fainsinger RL, et al. Definition and classification of cancer cachexia: an international consensus. Lancet Oncol. 2011 May;12(5):489-95.

9 Martin L, Birdsell L, Macdonald N, Reiman T, Clandinin MT, McCargar LJ, et al. Cancer cachexia in the age of obesity: skeletal muscle depletion is a powerful prognostic factor, independent of body mass index. J Clin Oncol. 2013 Apr;31(12):1539-47.

10 Xiao J, Mazurak VC, Olobatuyi TA, Caan BJ, Prado CM. Visceral adiposity and cancer survival: a review of imaging studies. Eur J Cancer Care (Engl). 2018 Mar;27(2):e12611.

11 Shachar SS, Williams GR, Muss HB, Nishijima TF. Prognostic value of sarcopenia in adults with solid tumours: A meta-analysis and systematic review. Eur J Cancer. 2016 Apr;57:58-67.

12 Nishikawa H, Shiraki M, Hiramatsu A, Moriya K, Hino K, Nishiguchi S. Japan Society of Hepatology guidelines for sarcopenia in liver disease (1st edition): Recommendation from the working group for creation of sarcopenia assessment criteria. Hepatol Res. 2016 Sep;46(10):951-63.

13 Sinclair M, Gow PJ, Grossmann M, Angus PW. Review article: sarcopenia in cirrhosis-aetiology, implications and potential therapeutic interventions. Aliment Pharmacol Ther. 2016 Apr;43(7):765-77.

14 Shen W, Punyanitya M, Wang Z, Gallagher D, St-Onge MP, Albu J, et al. Total body skeletal muscle and adipose tissue volumes: estimation from a single abdominal cross-sectional image. J Appl Physiol (1985). 2004 Dec; 97(6):2333-8.

15 van Vugt JL, Levolger S, Gharbharan A, Koek M, Niessen WJ, Burger JW, et al. A comparative study of software programmes for cross-sectional skeletal muscle and adipose tissue measurements on abdominal computed tomography scans of rectal cancer patients. J Cachexia Sarcopenia Muscle. 2017 Apr;8(2):285-97.

16 Prado CM. Body composition in chemotherapy: the promising role of CT scans. Curr Opin Clin Nutr Metab Care. 2013 Sep;16(5):525-33.

17 Chang KV, Chen JD, Wu WT, Huang KC, Hsu CT, Han DS. Association between Loss of Skeletal Muscle Mass and Mortality and Tumor Recurrence in Hepatocellular Carcinoma: A Systematic Review and Meta-Analysis. Liver Cancer. 2018 Mar; 7(1):90-103.

18 Fujiwara N, Nakagawa H, Kudo Y, Tateishi R, Taguri M, Watadani T, et al. Sarcopenia, intramuscular fat deposition, and visceral adiposity independently predict the outcomes of hepatocellular carcinoma.J Hepatol. 2015 Jul;63(1):131-40.

19 Saeki IY, Yamasaki T, Maeda M, Kawano R, Hisanaga T, Iwamoto T, Matsumoto T, et al. No Muscle Depletion with High Visceral Fat as a Novel Beneficial Biomarker of Sorafenib for Hepatocellular Carcinoma. Liver Cancer. 2018. https://doi.org/10.1159/000487858.

20 Hiraoka A, Hirooka M, Koizumi Y, Izumoto H, Ueki H, Kaneto M, et al. Muscle volume loss as a prognostic marker in hepatocellular carcinoma patients treated with sorafenib. Hepatol Res. 2017 May;47(6):558-65.

21 Imai K, Takai K, Hanai T, Ideta T, Miyazaki T, Kochi T, et al. Skeletal muscle depletion predicts the prognosis of patients with hepatocellular carcinoma treated with sorafenib. Int J Mol Sci. 2015 Apr;16(5):9612-24.

22 Mir O, Coriat R, Blanchet B, Durand JP, Boudou-Rouquette P, Michels J, et al. Sarcopenia predicts early doselimiting toxicities and pharmacokinetics of sorafenib in patients with hepatocellular carcinoma. PLoS One. 2012;7(5):e37563.

23 Nault JC, Pigneur F, Nelson AC, Costentin C, Tselikas L, Katsahian S, et al. Visceral fat area predicts survival in patients with advanced hepatocellular carcinoma treated with tyrosine kinase inhibitors. Dig Liver Dis. 2015 Oct;47(10):869-76.

24 Nishikawa H, Nishijima N, Enomoto H, Sakamoto A, Nasu A, Komekado H, et al. Prognostic significance of sarcopenia in patients with hepatocellular carcinoma undergoing sorafenib therapy. Oncol Lett. 2017 Aug; 14(2):1637-47.

25 Takada H, Kurosaki M, Nakanishi H, Takahashi Y, Itakura J, Tsuchiya K, et al. Impact of pre-sarcopenia in sorafenib treatment for advanced hepatocellular carcinoma. PLoS One. 2018 Jun;13(6):e0198812. 
26 Mittal S, El-Serag HB, Sada YH, Kanwal F, Duan Z, Temple S, et al. Hepatocellular Carcinoma in the Absence of Cirrhosis in United States Veterans is Associated With Nonalcoholic Fatty Liver Disease. Clin Gastroenterol Hepatol. 2016 Jan;14(1):124-31.e1.

27 Therasse P, Arbuck SG, Eisenhauer EA, Wanders J, Kaplan RS, Rubinstein L, et al. New guidelines to evaluate the response to treatment in solid tumors. European Organization for Research and Treatment of Cancer, National Cancer Institute of the United States, National Cancer Institute of Canada. J Natl Cancer Inst. 2000 Feb;92(3):205-16.

28 U.S. Department of Health and Human Services. Common Terminology Criteria for Adverse Events (CTCAE) Version 4.03. 2010 [updated 2010 June 14]. https://evs.nci.nih.gov/ftp1/CTCAE/CTCAE_4.03_2010-06-14_ QuickReference_8.5x1.pdf.

29 van Vledder MG, Levolger S, Ayez N, Verhoef C, Tran TC, Ijzermans JN. Body composition and outcome in patients undergoing resection of colorectal liver metastases. Br J Surg. 2012 Apr;99(4):550-7.

30 Verhoef C, van Dekken H, Hofland LJ, Zondervan PE, de Wilt JH, van Marion R, et al. Somatostatin receptor in human hepatocellular carcinomas: biological, patient and tumor characteristics. Dig Surg. 2008;25(1):21-6.

31 Iavarone M, Cabibbo G, Piscaglia F, Zavaglia C, Grieco A, Villa E, et al.; SOFIA (SOraFenib Italian Assessment) study group. Field-practice study of sorafenib therapy for hepatocellular carcinoma: a prospective multicenter study in Italy. Hepatology. 2011 Dec;54(6):2055-63.

32 Harimoto N, Shirabe K, Yamashita YI, Ikegami T, Yoshizumi T, Soejima Y, et al. Sarcopenia as a predictor of prognosis in patients following hepatectomy for hepatocellular carcinoma. Br J Surg. 2013 Oct;100(11):152330.

33 Levolger S, van Vledder MG, Muslem R, Koek M, Niessen WJ, de Man RA, et al. Sarcopenia impairs survival in patients with potentially curable hepatocellular carcinoma. J Surg Oncol. 2015 Aug;112(2):208-13.

34 Voron T, Tselikas L, Pietrasz D, Pigneur F, Laurent A, Compagnon P, et al. Sarcopenia Impacts on Short- and Long-term Results of Hepatectomy for Hepatocellular Carcinoma. Ann Surg. 2015 Jun;261(6):1173-83.

35 Antoun S, Baracos VE, Birdsell L, Escudier B, Sawyer MB. Low body mass index and sarcopenia associated with dose-limiting toxicity of sorafenib in patients with renal cell carcinoma. Ann Oncol. 2010 Aug;21(8):1594-8.

36 Reiss KA, Yu S, Mamtani R, Mehta R, D'Addeo K, Wileyto EP, et al. Starting Dose of Sorafenib for the Treatment of Hepatocellular Carcinoma: A Retrospective, Multi-Institutional Study. J Clin Oncol. 2017 Nov;35(31):357581.

37 Nishikawa $\mathrm{H}$, Enomoto $\mathrm{H}$, Ishii A, Iwata Y, Miyamoto $\mathrm{Y}$, Ishii N, et al. Elevated serum myostatin level is associated with worse survival in patients with liver cirrhosis. J Cachexia Sarcopenia Muscle. 2017 Dec;8(6):91525.

38 Ghassabian S, Rawling T, Zhou F, Doddareddy MR, Tattam BN, Hibbs DE, et al. Role of human CYP3A4 in the biotransformation of sorafenib to its major oxidized metabolites. Biochem Pharmacol. 2012 Jul;84(2):215-23.

39 Solheim TS, Laird BJ. Evidence base for multimodal therapy in cachexia. Curr Opin Support Palliat Care. 2012 Dec;6(4):424-31.

40 Marrero JA, Kudo M, Venook AP, Ye SL, Bronowicki JP, Chen XP, et al. Observational registry of sorafenib use in clinical practice across Child-Pugh subgroups: the GIDEON study. J Hepatol. 2016 Dec;65(6):1140-7. 